\title{
Article \\ The Prevalence of Advanced Interatrial Block and Its Relationship to Left Atrial Function in Patients with Transthyretin Cardiac Amyloidosis
}

\author{
Thomas Lindow $1,2,3, * \mathbb{C}$ and Per Lindquist $4(\mathbb{D}$ \\ 1 Kolling Institute, Royal North Shore Hospital, University of Sydney, Sydney, NSW 2065, Australia \\ 2 Department of Clinical Physiology, Research and Development, Växjö Central Hospital, \\ Region Kronoberg, 35188 Växjö, Sweden \\ 3 Clinical Physiology, Clinical Sciences, Lund University, 22100 Lund, Sweden \\ 4 Department of Clinical Physiology, Surgical and Perioperative Sciences, Umeå University, \\ 90187 Umeå, Sweden; per.lindqvist@umu.se \\ * Correspondence: Thomas.a.lindow@gmail.com; Tel.: +46-730-62-60-07
}

Citation: Lindow, T.; Lindqvist, P. The Prevalence of Advanced Interatrial Block and Its Relationship to Left Atrial Function in Patients with Transthyretin Cardiac Amyloidosis. J. Clin. Med. 2021, 10, 2764. https://doi.org/10.3390/ jcm10132764

Academic Editor: Roberto De Ponti

Received: 17 May 2021

Accepted: 22 June 2021

Published: 23 June 2021

Publisher's Note: MDPI stays neutral with regard to jurisdictional claims in published maps and institutional affiliations.

Copyright: (c) 2021 by the authors. Licensee MDPI, Basel, Switzerland. This article is an open access article distributed under the terms and conditions of the Creative Commons Attribution (CC BY) license (https:/ / creativecommons.org/licenses/by/ $4.0 /)$.

\begin{abstract}
Background: Advanced interatrial block (aIAB), which is associated with incident atrial fibrillation and stroke, occurs in the setting of blocked interatrial conduction. Atrial amyloid deposition could be a possible substrate for reduced interatrial conduction, but the prevalence of aIAB in patients with transthyretin cardiac amyloidosis (ATTR-CA) is unknown. We aimed to describe the prevalence of aIAB and its relationship to left atrial function in patients with ATTR-CA in comparison to patients with HF and left ventricular hypertrophy but no CA. Methods: The presence of aIAB was investigated among 75 patients (49 patients with ATTR-CA and 26 with HF but no CA). A comprehensive echocardiographic investigation was performed in all patients, including left atrial strain and strain rate measurements. Results: Among patients with ATTR-CA, 27\% had aIAB and in patients with HF but no CA, this figure was $21 \%,(p=0.78)$. The presence of aIAB was associated with a low strain rate during atrial contraction $\left(<0.91 \mathrm{~s}^{-1}\right)(\mathrm{OR}: 5.2(1.4-19.9))$, even after adjusting for age and LAVi (OR: 4.5 (1.0-19.19)). Conclusions: Advanced interatrial block is common among patients with ATTR-CA, as well as in patients with heart failure and left ventricular hypertrophy but no CA. aIAB is associated with reduced left atrial contractile function.
\end{abstract}

Keywords: interatrial block; left atrial strain; cardiac amyloidosis; transthyretin amyloid

\section{Introduction}

During atrial depolarization, the electrical impulses are propagated from the right to the left atrium through several conduction pathways, including inter-nodal tracts between the atria, e.g., Bachmann's bundle [1]. In the presence of a block in Bachmann's bundle, interatrial block (IAB) may occur. This block can occur with varying grades, from partial IAB resulting in increased $P$ wave duration only, to advanced IAB (aIAB) in which P wave duration is increased ( $\geq 120 \mathrm{~ms}$ ) and a biphasic $P$ wave pattern occurs in inferior leads (II, III, aVF) [2-5]. In case of a complete block in Bachmann's bundle, depolarization will follow a caudo-cranial route, in which the right atrium is depolarized first (caudal route) followed by a retrograde depolarization of the left atrium (cranial route, Figure 1) [6], which explains the biphasic P wave pattern in inferior leads.

IAB in combination with supraventricular arrhythmias is known as Bayes' syndrome [7]. aIAB, but not partial IAB, has been shown to be a significant predictor of new-onset and recurrent AF [8]. Furthermore, IAB is highly prevalent in patients with embolic stroke $[7,9,10]$. Due to the retrograde and delayed depolarization of the left atrium, poor left atrial electro-mechanical function is plausible, and this may predispose clot formation [9]. 


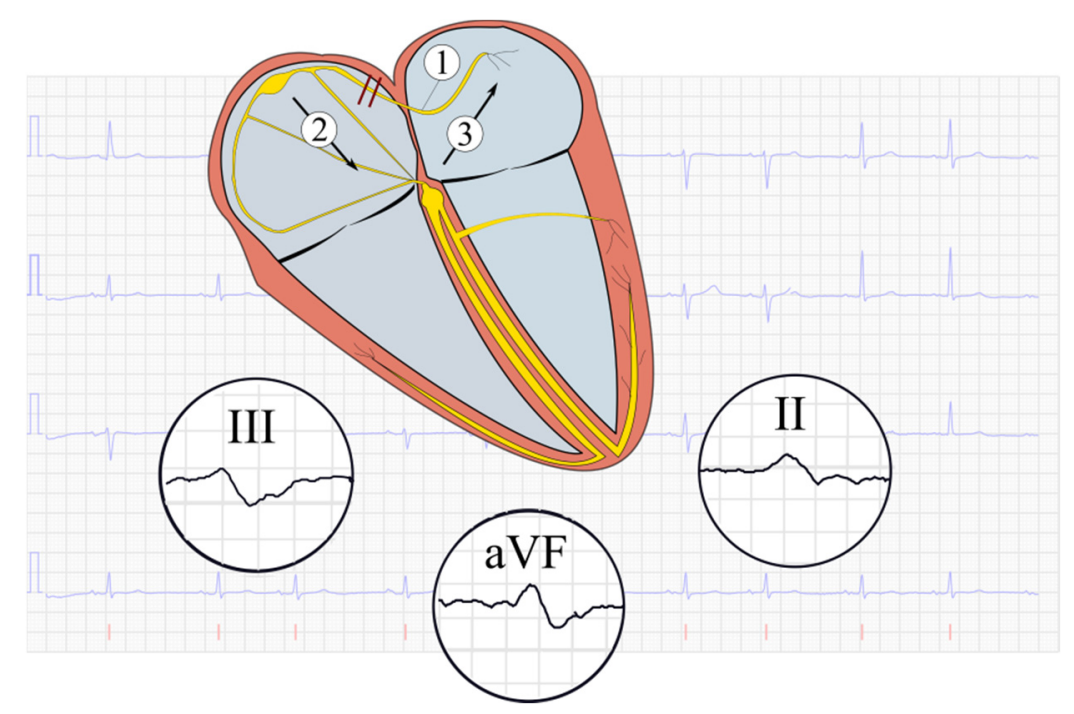

Figure 1. Description of the atrial depolarization route in advanced interatrial block with zoomed images of the P waves in inferior leads (II, aVF and III), in the case of a block in Bachmann's bundle (1). Normally, depolarization of the atria travels through the right and left atria through internodal tracts, e.g., Bachmann's bundle. Since impulse propagation from the right atrium to the left atrium is blocked, the right atrium will be depolarized first (2) followed by a retrograde depolarization of the left atrium (3), resulting in biphasic P waves in inferior leads. Modified from [10], reprinted with permission.

Transthyretin cardiac amyloidosis (ATTR-CA) has received increased attention in recent years, and prevalence of the disease has been reported to be markedly higher than previously expected [11]. For example, approximately one in eight patients undergoing transcatheter aortic valvular replacement [12] and about one in five patients with left ventricular hypertrophy and heart failure (HF) could be diagnosed with ATTR-CA [13]. ATTR-CA is nowadays an important clinical reality for both cardiologists [11] and radiologists [14]. In ATTR-CA, deposition of transthyretin (TTR) amyloid fibrils occurs in the extracellular space of the heart, affecting not only the ventricles but the atria, as well as resulting in impaired ventricular and atrial function [15-17]. In addition to HF, ATTR-CA is associated with increased risk of arrhythmias, in the form of both conduction abnormalities, such as bundle branch block or AV block, and atrial fibrillation [18-20]. It is plausible that conduction within the atrium, as well as between the atria, is affected by ATTR-CA, and that the prevalence of $\mathrm{aIAB}$ may therefore be increased in this population. Since both stroke and atrial fibrillation are common among patients with ATTR-CA [21,22], it is important to identify reliable predictors of such adverse events.

Our primary aim was to describe the prevalence of aIAB in patients with ATTR-CA in comparison to patients with HF and left ventricular hypertrophy but no CA. A secondary aim was to evaluate the association between $\mathrm{aIAB}$ and left atrial function.

\section{Material and Methods}

We performed an observational study including patients with increased left ventricular wall thickness and HF, previously included in a separate study on ATTR-CA [13]. In that study, out of 2238 patients with HF, cardiomyopathy or hypertensive heart disease based on hospital records (International Classification of Diseases 10 (ICD-10): I50, I42, I43 or I11), 174 patients had interventricular septal thickness (IVSd) exceeding $14 \mathrm{~mm}$ on echocardiography after re-evaluation of all patients reported to have IVSd $\geq 11 \mathrm{~mm}$. All patients were diagnosed for ATTR-CA by ${ }^{99 \mathrm{~m}} \mathrm{Tc}-3,3$-diphosphono-1,2-propanodicarboxylic acid $\left({ }^{99 \mathrm{~m}} \mathrm{Tc}-\mathrm{DPD}\right)$ scintigraphy, a reliable method for diagnosing ATTR-CA without the need for histology [23]. DPD scans were graded according to the Perugini classification (grade 0: no cardiac uptake with normal bone uptake (i.e., negative); grades 1 to 3: increasing 
cardiac uptake with increasing bone attenuation) [24]. Excluding amyloid light-chain (AL) amyloidosis in all patients was based on blood and urine analysis of serum-free light-chain abnormalities (Freelite, Binding Site reagent, reference range 0.27-1.64) and the absence of monoclonal bands. Patients with abnormalities in these analyses were carefully evaluated and their clinical history and disease progression reviewed to assess the possibility of them having AL amyloidosis. Sequencing of the TTR-gene was also undertaken in all patients to diagnose ATTRv (v for variant) amyloidosis. From this cohort, we found 11 patients with ATTRwt (wt for wild-type) and 26 patients with HF but no CA, all in sinus rhythm.

In addition, we retrospectively included 38 patients with ATTRv from our local database, all diagnosed with ATTR-CA based on positive DPD scintigraphy (grades 2-3) and genetic testing. All patients were in sinus rhythm.

\subsection{Electrocardiography}

Twelve-lead ECGs were recorded using computerized electrocardiographs (GE system Mac 5000/5500, General Electric, Chicago, IL, USA). Blinded ECG analysis was performed for all patients (TL). The ECG criteria for aIAB were $P$ wave duration $\geq 120 \mathrm{~ms}$ and biphasic $\mathrm{P}$ waves in leads II, III and aVF [6]. Atypical aIAB was defined as P wave duration $\geq 120 \mathrm{~ms}$ and biphasic P waves in leads III and aVF and an isodiphasic final component in lead II; or $P$ wave duration $\geq 120$ ms and biphasic $P$ waves in leads III and aVF and a triphasic P wave in lead II; or P wave duration $\geq 120 \mathrm{~ms}$ and a biphasic P wave in lead II and isodiphasic P waves in leads III and aVF; or P wave duration $\leq 120 \mathrm{~ms}$ but typical biphasic P waves in leads II, III and aVF [25].

\subsection{Echocardiography}

A comprehensive transthoracic echocardiographic exam was performed in all patients using a Vivid E9 system (GE Medical Systems, Horten, Norway) equipped with an adult 1.5-4.3 MHz phased array transducer. Offline analyses were performed using commercially available software (General Electric, EchoPac version BT 13, 113.0, Waukesha, WI, USA). Echocardiograms were digitally stored and were reanalyzed by an experienced operator (P.L.) blinded to the clinical diagnosis. Doppler variables to quantify left ventricular diastolic function were measured according to standard echocardiographic methods [26]. Left atrial (LA) measurements, including LA volume (LAV, LAV indexed to body surface area ([BSA] LAVi), LA strain and strain rate were measured at ventricular systole (LASs and LASRs) and atrial systole (LASa and LASRa)). When measuring LA strain and strain rate, anatomical landmarks were used and care was taken over echocardiographic image acquisition to ensure adequate LA tracking, avoiding foreshortening of the LA cavity or interference with the pulmonary veins or LA appendage. Longitudinal myocardial deformation, assessed by 2-dimensional echocardiography using speckle tracking, was analyzed offline. From the apical 4-chamber view, a point-and-click technique was used to create a horseshoe-shaped ROI within the LA. The endocardial border of the septal and the roof/apical and lateral walls of the LA were traced manually, in order to analyze global LA strain and strain-rate measurements, respectively. Tracings which did not accurately track LA structures were discarded. Reduced LA booster pump function was defined as strain rate during atrial contraction $(\mathrm{SRa})<0.91^{-\mathrm{s}}[27]$.

\subsection{Statistical Analysis}

Continuous variables are described using mean and standard deviation (SD) if normally distributed, otherwise as median and interquartile range (IQR). The Shapiro-Wilk test was used to test for normality. A $\chi^{2}$ test was used to assess proportional differences between groups. A Student's t-test or Mann-Whitney U test was used for comparisons of means or medians between groups for normally or non-normally distributed variables, respectively.

When evaluating the association between $\mathrm{aIAB}$ and LA function, no stratification based on ATTR-CA diagnosis was made, i.e., patients were stratified by aIAB despite their 
underlying condition. Odds ratios for reduced SRa were calculated using a univariate binary logistic regression model. Variables with $p$-values $<0.05$ at univariate analysis were entered into a multivariable model. Model improvement was evaluated by area under the curve (AUC). Statistical analysis was performed using IBM SPSS Statistics for Windows, Version 26.0, IBM Corp., Armonk, NY, USA).

\section{Results}

In total, 75 patients were included (49 patients with ATTR-CA and 26 with HF but no CA) (Figure 2). Baseline characteristics, including echocardiographic characteristics, are presented in Table 1.

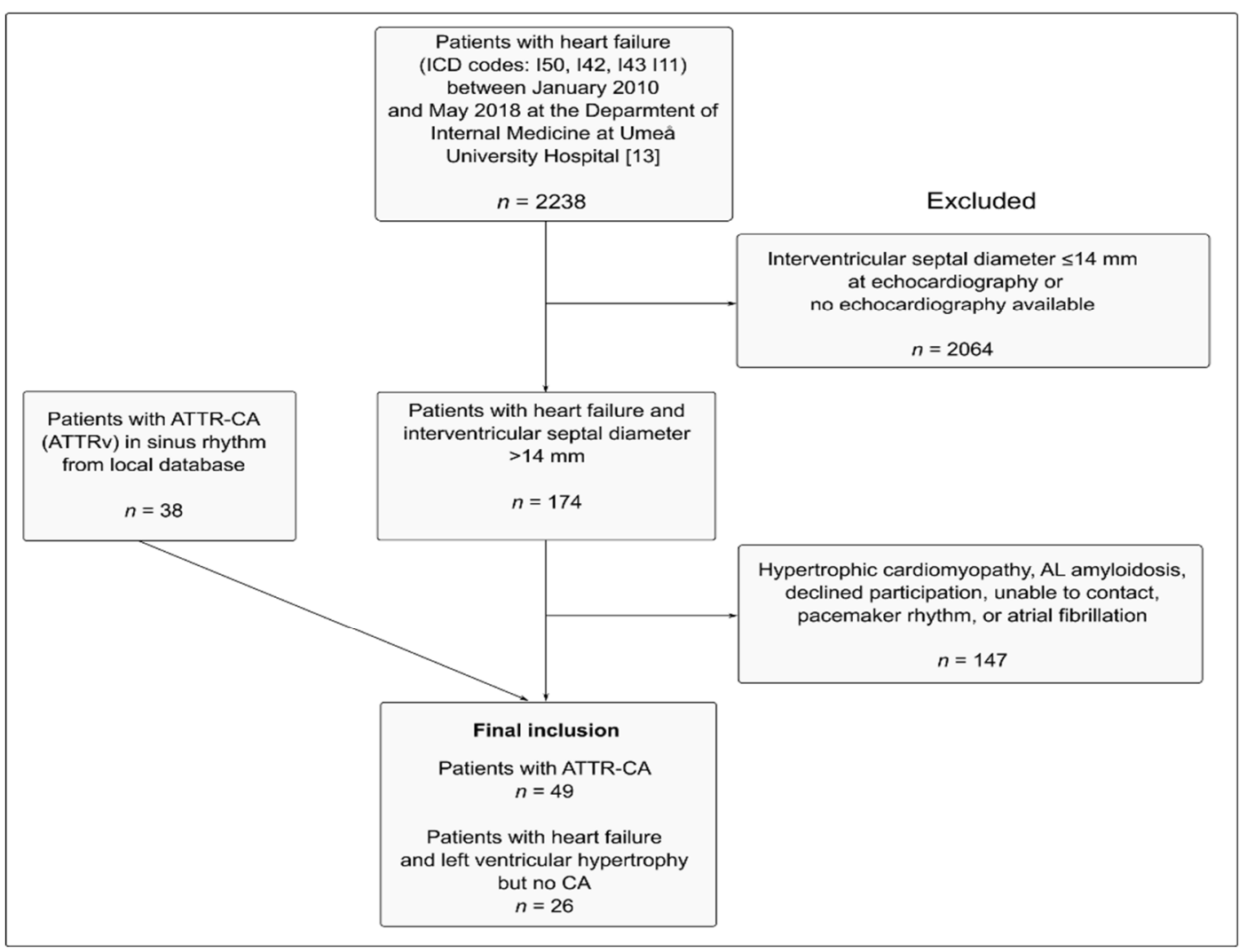

Figure 2. Flowchart of patient inclusion and exclusion. Abbreviations: ICD—International Classification of Diseases; ATTR-CA—transthyretin cardiac amyloidosis, ATTRv—amyloid transthyretin variant; AL—amyloid light-chain.

Table 1. Baseline and echocardiographic characteristics.

\begin{tabular}{|c|c|c|c|c|}
\hline & All Patients & HF No ATTR-CA & ATTR-CA & $p$-Value \\
\hline $\mathrm{n}$ & 75 & 26 & 49 & \\
\hline Age, years (mean (SD)) & $75.4(8.0)$ & $75.8(7.5)$ & $75.1(8.5)$ & 0.73 \\
\hline Body mass index (mean (SD)) & $26.0(4.8)$ & $29.2(5.5)$ & $24.9(4.1)$ & \\
\hline $\begin{array}{c}\text { Perugini score }(\%) \\
0 \\
1 \\
2 \\
3\end{array}$ & $\begin{array}{c}22(31.9) \\
3(4.3) \\
18(26.1) \\
26(37.7)\end{array}$ & $\begin{array}{c}22(100.0) \\
0(0.0) \\
0(0.0) \\
0(0.0)\end{array}$ & $\begin{array}{c}0(0.0) \\
3(6.4) \\
18(38.3) \\
26(55.3)\end{array}$ & $<0.001$ \\
\hline NT-ProBNP, ng/L (median (IQR)) & $782(231,1616)$ & $408(1216,5440)$ & $844(241,1640)$ & 0.42 \\
\hline Troponin T, ng/L (median (IQR)) & $25(16,40)$ & $22(13,34)$ & $30(19,45)$ & 0.27 \\
\hline Systolic BP, mm Hg (mean (SD)) & $137.6(20.0)$ & $145.4(23.2)$ & $133.3(16.9)$ & 0.01 \\
\hline Diastolic BP, mm Hg (mean (SD)) & $81.3(10.2)$ & $85.6(11.4)$ & $78.9(87)$ & 0.006 \\
\hline
\end{tabular}


Table 1. Cont.

\begin{tabular}{|c|c|c|c|c|}
\hline & All Patients & HF No ATTR-CA & ATTR-CA & $p$-Value \\
\hline Heart failure medications $(n, \%)$ & $52(69.3)$ & $25(96.2)$ & $27(55.1)$ & 0.001 \\
\hline LVDD, mm (mean (SD)) & $44.6(6.4)$ & $49.2(5.8)$ & $42.1(5.5)$ & $<0.001$ \\
\hline IVSD, mm (median (IQR)) & $16(15,20)$ & $16(15,17)$ & $18(15,21)$ & 0.067 \\
\hline PWT, mm (median (IQR)) & $13(10,14)$ & $11(9,12)$ & $13(12,15)$ & $<0.001$ \\
\hline LVEF, \% (median (IQR)) & $55(46,58)$ & $55(46,60)$ & $50(46,55)$ & 0.20 \\
\hline $\mathrm{E}, \mathrm{cm} / \mathrm{s}($ mean $(\mathrm{SD}))$ & $68.26(21.41)$ & $58.68(20.25)$ & $73.36(20.43)$ & 0.005 \\
\hline $\mathrm{e}^{\prime}, \mathrm{cm} / \mathrm{s}($ median (IQR)) & $4.0(3.8,6.0)$ & $4.0(3.0,5.0)$ & $5.0(4.0,6.0)$ & 0.07 \\
\hline E/e' (median (IQR)) & $14.9(12.8,16.7)$ & $14.0(11.3,16.2)$ & $15.2(13.318 .3)$ & 0.31 \\
\hline GLS, \% (mean (SD)) & $14.1(4.7)$ & $13.2(4.6)$ & $14.6(4.7)$ & 0.21 \\
\hline Relative wall thickness (median (IQR)) & $0.46(0.38,0.55)$ & $0.41(0.38,0.48)$ & $0.60(0.52,0.75)$ & 0.01 \\
\hline $\mathrm{LAVi}, \mathrm{mL} / \mathrm{m}^{2}($ mean $(\mathrm{SD}))$ & $40.54(16.61)$ & $41.00(18.80)$ & $39.38(10.13)$ & 0.82 \\
\hline $\begin{array}{l}\text { Tricuspid regurgitant velocity, } \mathrm{cm} / \mathrm{s} \\
\text { (mean (SD)) }\end{array}$ & $26.9(8.3)$ & $28.1(9.5)$ & $26.4(7.9)$ & 0.54 \\
\hline $\begin{array}{l}\text { Peak atrial longitudinal strain, \% } \\
\text { (median (IQR)) }\end{array}$ & $12.20(7.57,16.05)$ & $10.30(6.45,14.95)$ & $13.80(8.55,18.50)$ & 0.17 \\
\hline $\begin{array}{l}\text { Peak atrial longitudinal strain (atrial } \\
\text { contraction), } \% \text { (median (IQR)) }\end{array}$ & $8.32(5.15,12.15)$ & $8.16(6.10,10.75)$ & $8.32(5.00,14.00)$ & 0.74 \\
\hline $\begin{array}{c}\text { Atrial systolic strain rate, } \mathrm{s}^{-1} \\
\text { (median (IQR)) }\end{array}$ & $0.80(0.57,1.20)$ & $0.74(0.65,0.96)$ & $0.80(0.55,1.94)$ & 0.38 \\
\hline $\begin{array}{l}\text { Atrial strain rate (atrial contraction), } \mathrm{s}^{-1} \\
\text { (median (IQR)) }\end{array}$ & $0.81(0.52,1.20)$ & $0.88(0.57,1.20)$ & $0.81(0.46,1.10)$ & 0.64 \\
\hline
\end{tabular}

Abbreviations: HF-heart failure; ATTR-CA—transthyretin cardiac amyloidosis; SD—standard deviation; ProBNP—N-terminal pro b-type natriuretic peptide; $\mathrm{BP}$-blood pressure; LVDD—left ventricular diastolic diameter; IVSD—interventricular systolic diameter; PWTposterior wall thickness; LVEF—left ventricular ejection fraction; GLS—global longitudinal strain; IQR -interquartile range; LAVi—indexed left atrial volume.

\subsection{Prevalence of Advanced Interatrial Block in ATTR-CA}

Increased $\mathrm{P}$ wave duration $(\geq 120 \mathrm{~ms})$ was present in 54 patients $(43$ (54\%) ATTR-CA $11(39 \%)$ HF no CA, $p=0.25)$. Among patients with ATTR-CA, 8 patients $(16 \%)$ had typical aIAB and $5(10 \%)$ atypical aIAB. The prevalence of aIAB was not significantly higher in ATTR-CA compared to the reference group (27\% vs. $21 \%, p=0.67)$. The heart rate was higher among patients with ATTR-CA compared to those without. Left anterior hemiblock was more common among patients with ATTR-CA compared to those without. There was no difference in prevalence of the AV block or left bundle branch block. ECG findings are presented in Table 2.

Table 2. ECG findings stratified by ATTR diagnosis.

\begin{tabular}{|c|c|c|c|}
\hline & HF No ATTR-CA & ATTR-CA & $p$-Value \\
\hline$n$ & 26 & 49 & \\
\hline Heart rate, $\min ^{-1}$ (mean (SD)) & $64.7(12.5)$ & $74.8(11.6)$ & 0.001 \\
\hline $\mathrm{P}$ wave duration, ms (mean (SD)) & $103.1(20.2)$ & $112.0(22.0)$ & 0.09 \\
\hline P wave duration $\geq 120 \mathrm{~ms}(n, \%)$ & $10(38.5)$ & $25(51.0)$ & 0.43 \\
\hline Advanced $\operatorname{IA} \bar{B}(n, \%)$ & $5(21.4)$ & $13(26.5)$ & 0.67 \\
\hline Typical aIAB & $4(15.4)$ & $8(16.3)$ & \\
\hline Atypical aIAB & $1(3.8)$ & $5(10.2)$ & \\
\hline PR interval, ms (mean (SD)) & $199.8(37.7)$ & $211.8(38.4)$ & 0.20 \\
\hline AV-block I, ms $(n, \%)$ & $9(34.6)$ & $21(42.9)$ & 0.66 \\
\hline QRS duration, ms (median [IQR]) & $106(101,121)$ & $106(92,128)$ & 0.24 \\
\hline Left bundle branch block & $3(11.5)$ & $6(12.2)$ & 1.0 \\
\hline Left anterior hemiblock & $0(0)$ & $12(24.5)$ & 0.006 \\
\hline Right bundle branch block & $0(0)$ & $2(4.1)$ & 0.54 \\
\hline Right bundle branch block and left anterior hemiblock & $0(0)$ & $3(12.7)$ & 0.04 \\
\hline Pathological Q waves $(n, \%)$ & $2(7.7)$ & 7 (14.3) & 0.48 \\
\hline ST-segment changes $(n, \%)$ & $10(38.5)$ & $14(28.6)$ & 0.44 \\
\hline
\end{tabular}

Abbreviations: HF-heart failure; ATTR-CA—transthyretin cardiac amyloidosis; SD—standard deviation; IAB—interatrial block; AV— atrioventricular; IQR-interquartile range. 


\subsection{Advanced Interatrial Block and Left Atrial Function}

aIAB was present in 18 patients (13 with ATTR-CA). There were no statistically significant differences in mean age (79 vs. 76 years, $p=0.09)$, blood pressure $(131 / 79$ vs. $134 / 80 \mathrm{~mm} \mathrm{Hg}, p=0.50$ and 0.88$)$, body mass index ( $25.5 \mathrm{vs.} 24.5 \mathrm{~kg} / \mathrm{m}^{2}, p=0.44$ ) or the presence of heart failure medication $(85 \%$ vs. $71 \%, p=0.27)$ between patients with $\mathrm{IIAB}$ and patients without aIAB. Biomarker and echocardiographic findings in relation to $\mathrm{aIAB}$ are presented in Figure 2. Using strain analysis, there was a greater reduction in atrial function in patients with aIAB compared to those without (Figure 3), both for peak longitudinal LA strain and strain rate. AIAB was associated with low SRa $\left(<0.91 \mathrm{~s}^{-1}\right)$ (OR: 5.2 (1.4-19.9)) even after adjusting for age and LAVi (OR: 4.5 (1.0-19.19)) (Table 3). SRa was reduced in $83 \%$ of patients with aIAB, compared to $49 \%$ among those without $(p=0.04)$. The level of N-terminal pro-brain natriuretic peptides (NT-proBNP) was higher in patients with CA-ATTR and aIAB compared to those without aIAB (median (IQR): 1443 $(909,4344)$ vs. $942(262,2849))$, but did not reach statistical significance $(p=0.1)$.
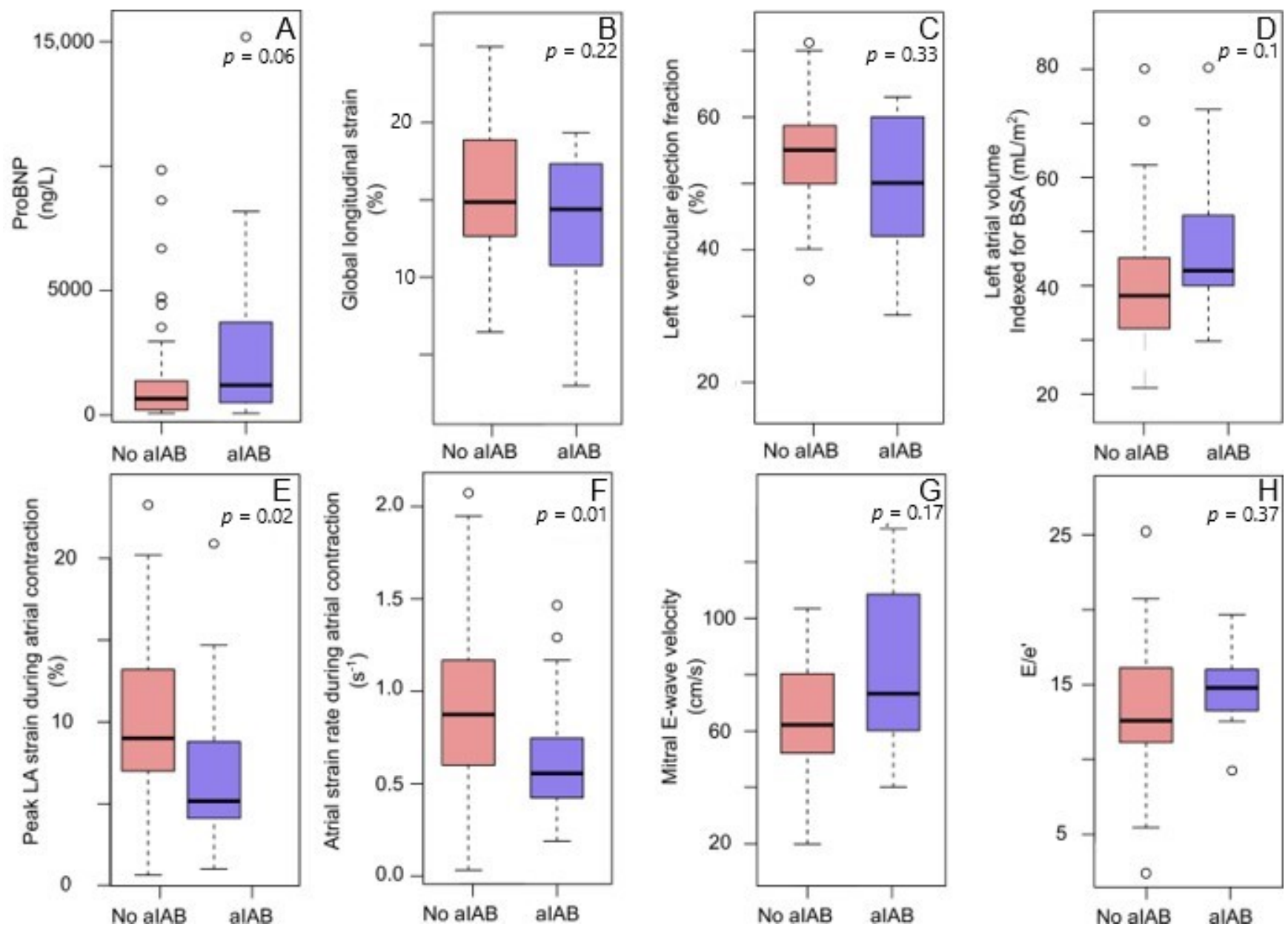

Figure 3. Biomarker and echocardiographic measures in patients with and without advanced interatrial block (aIAB). Patients without aIAB are presented in red bars and patients with aIAB in blue bars. Upper panel: (A) N-terminal pro b-type natriuretic peptide (proBNP); (B) global longitudinal strain; (C) left ventricular ejection fraction; (D) left atrial volume indexed for body surface area (BSA); (E) peak left atrial (LA) strain during atrial contraction; (F) atrial strain rate during atrial contraction; $(\mathbf{G})$ mitral E-wave velocity; $(\mathbf{H})$ E/e'. Peak left atrial longitudinal strain $(\mathbf{E})$ and atrial strain rate $(\mathbf{F})$ were significantly reduced in patients with advanced interatrial block. Peak left atrial longitudinal strain (E) and atrial strain rate (F) were significantly reduced in patients with advanced interatrial block. 
Table 3. Univariate and multivariable analysis.

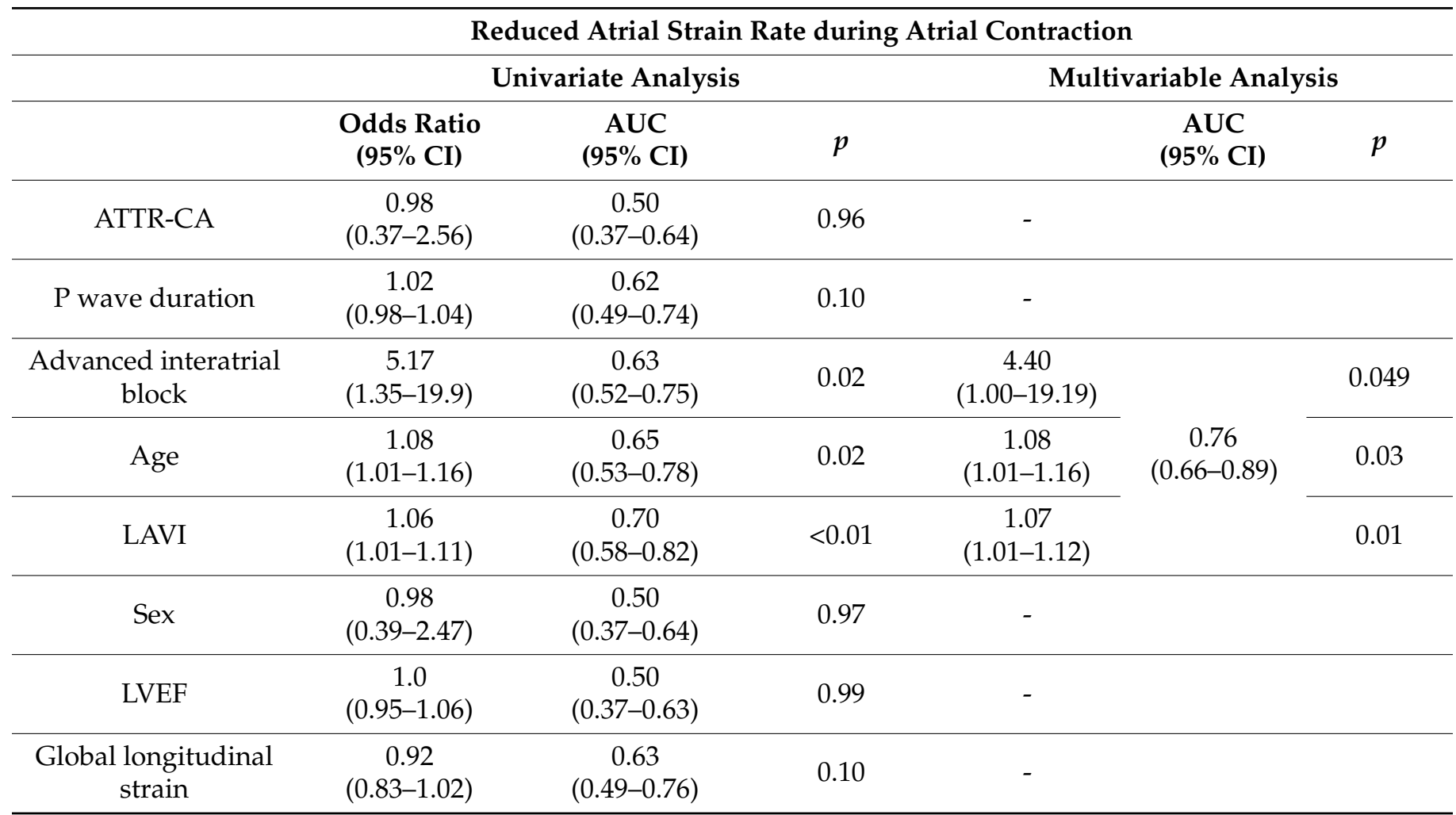

Abbreviations: AUC—area under the curve; ATTR-CA—-transthyretin cardiac amyloidosis; CI-confidence interval; LAVI-indexed left atrial volume; LVEF-left ventricular ejection fraction.

\section{Discussion}

This is the first study to describe the prevalence of aIAB in patients with ATTR-CA, which we found to be high $(27 \%)$. Although the possible presence of atrial amyloid deposition was a theoretically appealing substrate for reduced interatrial conduction, the prevalence was not significantly higher than among patients with HF and left ventricular hypertrophy but no CA. Nonetheless, the high prevalence is clinically relevant. Firstly, it may add to the stroke-risk assessment in patients with ATTR-CA. ATTR-CA is associated with a high risk of stroke in itself and independently of conventional risk assessment, such as left atrial size or $\mathrm{CHA}_{2} \mathrm{DS}_{2}$-VASc score [21], and aIAB has been shown to be associated with increased risk of stroke $[7,28,29]$. Atrial fibrillation is common among patients with ATTR-CA [22], but although atrial fibrillation is a well-established risk factor for stroke, the reported lack of temporal relation suggests that it may not be the direct cause of embolism [30]. Instead, it can be considered (another) risk factor and marker of atrial disease [31]. Identifying additional prognostically relevant markers of atrial disease, both electrocardiographic and echocardiographic ones (e.g., aIAB, LA strain, etc.), is important. Secondly, early identification of atrial fibrillation is important in ATTR-CA. Maintained sinus rhythm has been shown to be associated with improved survival, and strategies (both medical and invasive) are more effective in the earlier stages of the disease [22]. Advanced IAB by resting 12-lead ECG is an easily accessible marker for the identification of patients with a high risk of atrial fibrillation and can be used to indicate which patients should undergo further investigations to detect paroxysmal atrial fibrillation, such as long-term ECG recordings.

In congestive heart failure, the atria are commonly affected by fibrosis [17]. This may explain the high prevalence of aIAB in HF patients. Out of 390 patients with HF undergoing cardiac resynchronization therapy, $38 \%$ were found to have aIAB. In that population, aIAB independently predicted the development of new-onset atrial fibrillation [32]. 
In recent years, aIAB has been reported for other populations as well, such as patients treated with transcatheter aortic valve implantation (12\%) [33], patients with ST-elevation myocardial infarction (6\%) [34] or takotsubo cardiomyopathy (5\%) [35], patients with human immunodeficiency virus (4\%) [36], etc.

Lacalzada-Almeida et al. performed an observational prospective study in which they followed 98 patients scheduled for a preoperative ECG before non-cardiac surgery for almost 2 years. Advanced IAB was present in $22 \%$ of patients. New atrial fibrillation or stroke occurred in $15 \%$ without IAB, and in $41 \%$ of those with aIAB. In that study, reduced SRa was the strongest predictor of incident AF or stroke [37]. Nochioka et al. described impaired LA function in patients with different subtypes of CA. LA active emptying function was worse in wild-type ATTR compared to other types of CA [38]. In the present study, we found a significant association between $\mathrm{aIAB}$ and reduced LA function, even after adjusting for left atrial size and age.

Amyloid deposition in the atria also occurs in age-related degenerative diseases other than ATTR, and can even occur as an isolated atrial disease [17]. Atrial amyloidosis is recognized as a class IV atrial cardiomyopathy, according to a recent consensus document [17]. Atrial fibrosis resulting in conduction inhomogeneity has been suggested to be an arrhythmogenic substrate [39]. Two decades ago, Röcken et al. obtained tissue samples from the right atrial appendage in patients undergoing cardiac surgery and found that amyloid deposition was independently associated with an increased risk of atrial fibrillation [15]. In another study, it was shown that among patients with ATTR-CA (ATTRv), reduced atrial function can occur even in in the absence of LA dilatation, supposedly due to a limitation of LA distension by amyloid deposition. In that cohort, reduced SRa independently predicted atrial arrhythmia [40].

This study is limited by its retrospective design. In addition, although the ECG reader (T.L.) was blinded to the clinical outcome, among patients with imaging evidence of left ventricular hypertrophy, CA can be suspected based on the absence of electrocardiographic findings of left ventricular hypertrophy or reduced QRS amplitudes, and thus blinding could not be considered complete. Nonetheless, T.L. was blinded to the echocardiographic results for all patients. Additionally, echocardiographic measurements were performed by a single (highly experienced) reader only (P.L.). LA strain and strain rate values have proven to be highly reproducible, and SRa in particular had the highest intra- and interobserver agreement [41].

Additionally, the sample size is small and the lack of significant differences in prevalence of aIAB between ATTR-CA and patients with HF but no CA may be due to a type II error. However, the prevalence of $\mathrm{AIAB}$ was high among patients with ATTR-CA, a finding that is clinically relevant despite the lack of difference between the two groups.

\section{Conclusions}

Advanced interatrial block is common among patients with ATTR-CA, but not more common than among patients with $\mathrm{HF}$ and left ventricular hypertrophy but no CA. aIAB is associated with reduced LA phasic function independently of age and LA size.

Author Contributions: Conceptualization, T.L.; methodology, T.L. and P.L.; validation, P.L.; formal analysis, T.L.; investigation, P.L.; resources, P.L.; data curation, P.L.; writing-original draft preparation, T.L.; writing-review and editing, P.L.; visualization, T.L.; supervision, P.L.; project administration, P.L.; funding acquisition, P.L. Both authors have read and agreed to the published version of the manuscript. All authors have read and agreed to the published version of the manuscript.

Funding: The study was supported by The Swedish Heart and Lung foundation, grants no 20160787 and 20200160 and The Swedish Research Council grant no 2019-01338. TL is currently under the support of postdoctoral research grants from The Swedish Heart-Lung Foundation (grant no 20200553), the Swedish Cardiac Society, the Royal Swedish Academy of Sciences (grant no LM20190013), Women \& Health Foundation, Region Kronoberg (grant no 8301), The Swedish Heart and Lung Association (grant no LKH1387), Swedish Association of Clinical Physiology, and the Scandinavian Society of Clinical Physiology \& Nuclear Medicine. 
Institutional Review Board Statement: The study was conducted according to the guidelines of the Declaration of Helsinki, and approved by the Institutional Ethics Committee at Umeå University (protocol code 2016-435-31M (07 February 2017), 2018-418-32M (26 April 2018), 2018-137-32M (26 November 2018))

Informed Consent Statement: Informed consent was obtained from all subjects involved in the study.

Data Availability Statement: The data presented in this study are available on request from the corresponding author. The data are not publicly available due to ethical and privacy reasons.

Conflicts of Interest: The authors declare no conflict of interest.

\section{References}

1. De Ponti, R.; Ho, S.Y.; Salerno-Uriarte, J.A.; Tritto, M.; Spadacini, G. Electroanatomic analysis of sinus impulse propagation in normal human atria. J. Cardiovasc. Electrophysiol. 2002, 13, 1-10. [CrossRef]

2. Roithinger, F.X.; Cheng, J.; SippensGroenewegen, A.; Lee, R.J.; Saxon, L.A.; Scheinman, M.M.; Lesh, M.D. Use of Electroanatomic Mapping to Delineate Transseptal Atrial Conduction in Humans. Circulation 1999, 100, 1791-1797. [CrossRef]

3. Markides, V.; Schilling, R.J.; Ho, S.Y.; Chow, A.W.; Davies, D.W.; Peters, N.S. Characterization of Left Atrial Activation in the Intact Human Heart. Circulation 2003, 107, 733-739. [CrossRef]

4. Mitrofanova, L.; Ivanov, V.; Platonov, P.G. Anatomy of the inferior interatrial route in humans. Europace 2005, 7, S49-S55. [CrossRef]

5. Ariyarajah, V.; Spodick, D.H. The Bachmann Bundle and Interatrial Conduction. Cardiol. Rev. 2006, 14, 194-199. [CrossRef]

6. de Luna, A.B.; Platonov, P.; Cosio, F.G.; Cygankiewicz, I.; Pastore, C.; Baranowski, R.; Spodick, D. Interatrial blocks. A separate entity from left atrial enlargement: A consensus report. J. Electrocardiol. 2012, 45, 445-451. [CrossRef] [PubMed]

7. De Luna, A.B.; Martínez-Sellés, M.; Bayés-Genís, A.; Elosua, R.; Baranchuk, A. Surface ECG interatrial block-guided treatment for stroke prevention: Rationale for an attractive hypothesis. BMC Cardiovasc. Disord. 2017, 17, 211.

8. Tse, G.; Wong, C.W.; Gong, M.; Wong, W.T.; Bazoukis, G.; Wong, S.H.; Li, G.; Wu, W.K.; Tse, L.A.; Lampropoulos, K.; et al. Predictive value of inter-atrial block for new onset or recurrent atrial fibrillation: A systematic review and meta-analysis. Int. J. Cardiol. 2018, 250, 152-156. [CrossRef]

9. Chhabra, L.; Devadoss, R.; Chaubey, V.K.; Spodick, D.H. Interatrial Block in the Modern Era. Curr. Cardiol. Rev. 2014, 10, 181-189. [CrossRef]

10. Lindow, T.; Baranchuk, A. Interatrial block and ischemic stroke. J. Thorac. Dis. 2018, 10, 7052-7054. [CrossRef] [PubMed]

11. Ruberg, F.L.; Grogan, M.; Hanna, M.; Kelly, J.W.; Maurer, M.S. Transthyretin Amyloid Cardiomyopathy. J. Am. Coll. Cardiol. 2019, 73, 2872-2891. [CrossRef]

12. Nitsche, C.; Scully, P.R.; Patel, K.P.; Kammerlander, A.A.; Koschutnik, M.; Dona, C.; Wollenweber, T.; Ahmed, N.; Thornton, G.D.; Kelion, A.D.; et al. Prevalence and Outcomes of Concomitant Aortic Stenosis and Cardiac Amyloidosis. J. Am. Coll. Cardiol. 2021, 77, 128-139. [CrossRef] [PubMed]

13. Lindmark, K.; Pilebro, B.; Sundström, T.; Lindqvist, P. Prevalence of wild type transtyrethin cardiac amyloidosis in a heart failure clinic. ESC Heart Fail. 2020, 8, 745-749. [CrossRef] [PubMed]

14. Bianco, M.; Parente, A.; Biolè, C.; Righetti, C.; Spirito, A.; Luciano, A.; Destefanis, P.; Nangeroni, G.; Angusti, T.; Anselmino, M.; et al. The prevalence of TTR cardiac amyloidosis among patients undergoing bone scintigraphy. J. Nucl. Cardiol. 2021, 1-6. [CrossRef]

15. Röcken, C.; Peters, B.; Juenemann, G. Atrial amyloidosis. An arrhythmogenic substrate for persistent atrial fibrillation. ACC Curr. J. Rev. 2003, 12, 86-87. [CrossRef]

16. Di Bella, G.; Minutoli, F.; Madaffari, A.; Mazzeo, A.; Russo, M.; Donato, R.; Zito, C.; Aquaro, G.D.; Piccione, M.C.; Pedri, S.; et al. Left atrial function in cardiac amyloidosis. J. Cardiovasc. Med. 2016, 17, 113-121. [CrossRef]

17. Goette, A.; Kalman, J.M.; Aguinaga, L.; Akar, J.; Cabrera, J.A.; Chen, S.A.; Chugh, S.S.; Corradi, D.; D’avila, A.; Dobrev, D.; et al. EHRA/HRS/APHRS/SOLAECE expert consensus on Atrial cardiomyopathies: Definition, characterisation, and clinical implication. J. Arrhythmia 2016, 32, 247-278. [CrossRef] [PubMed]

18. Feng, D.; Syed, I.S.; Martinez, M.; Oh, J.K.; Jaffe, A.S.; Grogan, M.; Edwards, W.D.; Gertz, M.A.; Klarich, K.W. Intracardiac Thrombosis and Anticoagulation Therapy in Cardiac Amyloidosis. Circulation 2009, 119, 2490-2497. [CrossRef]

19. Maurer, M.S.; Bokhari, S.; Damy, T.; Dorbala, S.; Drachman, B.M.; Fontana, M.; Grogan, M.; Kristen, A.V.; Lousada, I.; NativiNicolau, J.; et al. Expert Consensus Recommendations for the Suspicion and Diagnosis of Transthyretin Cardiac Amyloidosis. Circulation Hear. Fail. 2019, 12, e006075. [CrossRef]

20. Maurer, M.S.; Hanna, M.; Grogan, M.; Dispenzieri, A.; Witteles, R.; Drachman, B.; Judge, D.P.; Lenihan, D.J.; Gottlieb, S.S.; Shah, J.S.; et al. Genotype and Phenotype of Transthyretin Cardiac Amyloidosis: THAOS (Transthyretin Amyloid Outcome Survey). J. Am. Coll. Cardiol. 2016, 68, 161-172. [CrossRef]

21. Bukhari, S.; Barakat, A.F.; Eisele, Y.S.; Nieves, R.; Jain, S.; Saba, S.; Follansbee, W.P.; Brownell, A.; Soman, P. Prevalence of Atrial Fibrillation and Thromboembolic Risk in Wild-Type Transthyretin Amyloid Cardiomyopathy. Circulation 2021, 143, 1335-1337. [CrossRef] 
22. Donnellan, E.; Wazni, O.M.; Hanna, M.; Elshazly, M.B.; Puri, R.; Saliba, W.; Kanj, M.; Vakamudi, S.; Patel, D.R.; Baranowski, B.; et al. Atrial Fibrillation in Transthyretin Cardiac Amyloidosis: Predictors, Prevalence, and Efficacy of Rhythm Control Strategies. JACC. Clin. Electrophysiol. 2020, 6, 1118-1127. [CrossRef] [PubMed]

23. Gillmore, J.D.; Maurer, M.S.; Falk, R.H.; Merlini, G.; Damy, T.; Dispenzieri, A.; Wechalekar, A.D.; Berk, J.L.; Quarta, C.C.; Grogan, M.; et al. Nonbiopsy Diagnosis of Cardiac Transthyretin Amyloidosis. Circulation 2016, 133, 2404-2412. [CrossRef] [PubMed]

24. Perugini, E.; Guidalotti, P.L.; Salvi, F.; Cooke, R.M.; Pettinato, C.; Riva, L.; Leone, O.; Farsad, M.; Ciliberti, P.; Reggiani, M.L.B.;

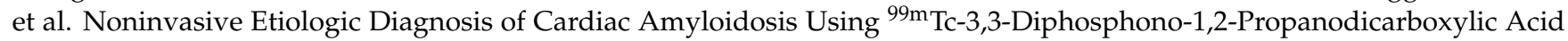
Scintigraphy. J. Am. Coll. Cardiol. 2005, 46, 1076-1084. [CrossRef] [PubMed]

25. de Luna, A.B.; Escobar-Robledo, L.A.; Aristizabal, D.; Restrepo, D.W.; Mendieta, G.; van Roessel, A.M.; Elosua, R.; Bayés-Genís, A.; Martínez-Sellés, M.; Baranchuk, A.; et al. Atypical advanced interatrial blocks: Definition and electrocardiographic recognition. J. Electrocardiol. 2018, 51, 1091-1093. [CrossRef] [PubMed]

26. Mitchell, C.; Rahko, P.S.; Blauwet, L.A.; Canaday, B.; Finstuen, J.A.; Foster, M.C.; Horton, K.; Ogunyankin, K.O.; Palma, R.A.; Velazquez, E.J. Guidelines for Performing a Comprehensive Transthoracic Echocardiographic Examination in Adults: Recommendations from the American Society of Echocardiography. J. Am. Soc. Echocardiogr. 2019, 32, 1-64. [CrossRef]

27. Morris, D.A.; Takeuchi, M.; Krisper, M.; Köhncke, C.; Bekfani, T.; Carstensen, T.; Hassfeld, S.; Dorenkamp, M.; Otani, K.; Takigiku, K.; et al. Normal values and clinical relevance of left atrial myocardial function analysed by speckle-tracking echocardiography: Multicentre study. Europace Heart J. Cardiovasc. Imaging 2015, 16, 364-372. [CrossRef]

28. Bayés-De-Luna, A.; Martínez-Sellés, M.; Elosua, R.; Bayés-Genís, A.; Mendieta, G.; Baranchuk, A.; Breithardt, G. Relation of Advanced Interatrial Block to Risk of Atrial Fibrillation and Stroke. Am. J. Cardiol. 2020, 125, 1745-1748. [CrossRef]

29. Escobar-Robledo, L.A.; Bayés-De-Luna, A.; Lupón, J.; Baranchuk, A.; Moliner, P.; Martínez-Sellés, M.; Zamora, E.; de Antonio, M.; Domingo, M.; Cediel, G.; et al. Advanced interatrial block predicts new-onset atrial fibrillation and ischemic stroke in patients with heart failure: The "Bayes' Syndrome-HF" study. Int. J. Cardiol. 2018, 271, 174-180. [CrossRef] [PubMed]

30. Brambatti, M.; Connolly, S.J.; Gold, M.R.; Morillo, C.; Capucci, A.; Muto, C.; Lau, C.P.; Van Gelder, I.C.; Hohnloser, S.H.; Carlson, M.; et al. Temporal Relationship Between Subclinical Atrial Fibrillation and Embolic Events. Circulation 2014, 129, $2094-2099$. [CrossRef]

31. Bayés de Luna, A.; Baranchuk, A.; Martínez-Sellés, M.; Platonov, P.G. Anticoagulation in patients at high risk of stroke without documented atrial fibrillation. Time for a paradigm shift? Ann. Noninvasive Electrocardiol. 2017, 22, e12417. [CrossRef] [PubMed]

32. Sadiq Ali, F.; Enriquez, A.; Conde, D.; Redfearn, D.; Michael, K.; Simpson, C.; Abdollah, H.; de Luna, A.B.; Hopman, W.; Baranchuk, A. Advanced Interatrial Block Predicts New Onset Atrial Fibrillation in Patients with Severe Heart Failure and Cardiac Resynchronization Therapy. Ann. Noninvasive Electrocardiol. 2015, 20, 586-591. [CrossRef]

33. Vicent, L.; Fernández-Cordón, C.; Nombela-Franco, L.; Escobar-Robledo, L.A.; Ayesta, A.; Solé, A.A.; Gómez-Doblas, J.J.; Bernal, E.; Tirado-Conte, G.; Cobiella, J.; et al. Baseline ECG and Prognosis After Transcatheter Aortic Valve Implantation: The Role of Interatrial Block. J. Am. Hear. Assoc. 2020, 9, e017624. [CrossRef] [PubMed]

34. Bruña, V.; Velásquez-Rodríguez, J.; Valero-Masa, M.J.; Pérez-Guillem, B.; Vicent, L.; Díez-Delhoyo, F.; Devesa, C.; SousaCasasnovas, I.; Juárez, M.; De Luna, A.B.; et al. Prognostic of Interatrial Block after an Acute ST-Segment Elevation Myocardial Infarction. Cardiology 2019, 142, 109-115. [CrossRef] [PubMed]

35. Martín-Demiguel, I.; Núñez-Gil, I.J.; Pérez-Castellanos, A.; Vedia, O.; Uribarri, A.; Durán-Cambra, A.; Martín-García, A.; CorbíPascual, M.; Marzo, M.G.; Martínez-Sellés, M. Prevalence and Significance of Interatrial Block in Takotsubo Syndrome (from the RETAKO Registry). Am. J. Cardiol. 2019, 123, 2039-2043. [CrossRef]

36. Fanjul, F.; Campins, A.; Asensio, J.; Sampériz, G.; Yañez, A.; Romaguera, D.; Fiol, M.; Riera, M. Interatrial blocks prevalence and risk factors for human immunodeficiency virus-infected persons. PLoS ONE 2019, 14, e0223777. [CrossRef]

37. Lacalzada-Almeida, J.; Izquierdo-Gómez, M.M.; García-Niebla, J.; Elosua, R.; Jiménez-Sosa, A.; Baranchuk, A.; Bayes de Luna, A. Advanced interatrial block is a surrogate for left atrial strain reduction which predicts atrial fibrillation and stroke. Ann. Noninvasive Electrocardiol. 2019, 24, e12632. [CrossRef]

38. Nochioka, K.; Quarta, C.C.; Claggett, B.; Roca, G.Q.; Rapezzi, C.; Falk, R.H.; Solomon, S.D. Left atrial structure and function in cardiac amyloidosis. Europace Hear. J. Cardiovasc. Imaging 2017, 18, 1128-1137. [CrossRef]

39. Li, D.; Fareh, S.; Leung, T.K.; Nattel, S. Promotion of atrial fibrillation by heart failure in dogs: Atrial remodeling of a different sort. Circulation 1999, 100, 87-95. [CrossRef]

40. Henein, M.Y.; Suhr, O.B.; Arvidsson, S.; Pilebro, B.; Westermark, P.; Hörnsten, R.; Lindqvist, P. Reduced left atrial myocardial deformation irrespective of cavity size: A potential cause for atrial arrhythmia in hereditary transthyretin amyloidosis. Amyloid 2018, 25, 46-53. [CrossRef] [PubMed]

41. Rausch, K.; Shiino, K.; Putrino, A.; Lam, A.K.-Y.; Scalia, G.M.; Chan, J. Reproducibility of global left atrial strain and strain rate between novice and expert using multi-vendor analysis software. Int. J. Cardiovasc. Imaging 2018, 35, 419-426. [CrossRef] [PubMed] 